\title{
Views of children and parents on limiting unhealthy food, drink and alcohol sponsorship of elite and children's sports
}

\author{
Bridget Kelly ${ }^{1}{ }^{*}$, Louise A Baur ${ }^{1}$, Adrian E Bauman ${ }^{1}$, Lesley King ${ }^{1}$, Kathy Chapman ${ }^{2}$ \\ and Ben J Smith ${ }^{3}$ \\ ${ }^{1}$ Prevention Research Collaboration, School of Public Health, Level 2 - Medical Foundation Building (K25), \\ University of Sydney, Sydney, NSW 2006, Australia: ${ }^{2}$ Cancer Council NSW, Sydney, Australia: ${ }^{3}$ Department of \\ Health Social Science, Monash University, Melbourne, Australia
}

Submitted 1 November 2011: Final revision received 14 March 2012: Accepted 15 March 2012: First published online 11 May 2012

\begin{abstract}
Objective: To determine parents' and children's attitudes towards food, beverage and alcohol sponsorship of elite and children's sports and the acceptability of policies and alternative funding models to limit this sponsorship.

Design: Telephone surveys were conducted with parents in February-May 2011. One child from each household was invited to complete an online survey. Surveys assessed parents' perceptions about the influence of sponsorship on children and support for limiting sponsorship, and children's awareness of and attitudes towards sponsors.

Setting: Randomly sampled households in New South Wales, Australia.

Subjects: Parents ( $n$ 825) and children aged 10-16 years ( $n$ 243).

Results: Three-quarters of parents supported the introduction of policies to restrict unhealthy food, beverage and alcohol sponsorship of children's and elite sports. More parents ( $81 \%$ ) supported the introduction of alternative funding models to allow these companies to sponsor sport provided there was no visible branding. Two-thirds of children recalled sponsors of their favourite elite sports team/athlete, with 428 sponsors recalled. Of these, 11\% were food/beverage companies and 3\% were alcohol-related. For 39\% of sponsors, children reported feeling better about the company after it had sponsored a team/athlete.

Conclusions: Australian parents support restrictions on unhealthy food, beverage and alcohol sport sponsorship. Children's positive associations regarding sponsors are likely to be linked to brand preferences and usage.
\end{abstract}

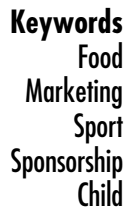

relating to tobacco and alcohol sponsorship have demonstrated that sponsorship has an impact on product recall and product-related attitudes and behavioural intentions $^{(6)}$. This body of research has identified that sponsorship increases brand recall ${ }^{(7)}$, favourable attitudes to brands ${ }^{(8,9)}$, purchasing behaviours ${ }^{(10)}$ and ultimately product consumption ${ }^{(7)}$. Evidence that alcohol sponsorship can create positive associations between alcohol and sport has led to calls to also limit this form of sponsorship ${ }^{(11)}$. In particular, in a study of 1279 adults who competed in sport in Australia, half of these sportspeople received sponsorship from alcohol-related businesses and companies $^{(12)}$. Those sportspeople personally receiving alcohol sponsorship had significantly higher scores on the Alcohol Use Disorders Identification Test, with higher scores related to hazardous levels of drinking ${ }^{(12)}$.

Theoretically, the relationship between food and beverage sponsorship and individuals' consumption behaviours may follow a similar pathway to that established for tobacco 
and alcohol ${ }^{(12,13)}$. Furthermore, in one small study with 103 children attending Australian sports clubs, children had a high recall of food and beverage sponsors of their clubs $^{(14)}$. The effects of this marketing on children are also likely to be more pronounced than for adults given that children are more likely to be unaware of its commercial and persuasive purpose ${ }^{(15)}$.

The present paper reports on a survey aimed to determine parents' and children's awareness of, and attitudes towards, food, beverage and alcohol sponsorship of elite and children's sports, and the acceptability of regulatory mechanisms to limit this sponsorship. The survey extends earlier interviews with parents and children at sports clubs $^{(14,16)}$, by determining if the findings are more broadly applicable.

\section{Methods}

\section{Sampling}

Households in New South Wales (NSW), Australia were randomly sampled from an electronic database of the 2009 White Pages directory, which represents a reliable, comprehensive and contemporary listing of residential numbers ${ }^{(16)}$. Sample numbers were cross-checked with postcodes to ensure these were drawn from NSW, with representation of all area health service regions (as at 2010). Numbers were then randomised using a computerbased randomiser and an every $n$th selection method was used to select the sample of numbers. Additional numbers, as required, were again selected using this method from the randomised list of sample numbers, after excluding those numbers that had already been sampled. Eligible parents/guardians included those with a child aged 5-16 years who participated in organised sport. Eligible children/adolescents included those aged 10-16 years who played organised sport. In $2009,60 \%$ of children aged 5-14 years participated in organised sport in NSW ${ }^{(17)}$. Study approval was granted by The University of Sydney Human Ethics Committee.

\section{Measures}

Two questionnaires were developed, based on studies measuring awareness of sponsorship ${ }^{(6)}$ and support of regulations to limit unhealthy sponsorship ${ }^{(16,18)}$. The parent questionnaire addressed: (i) demographic characteristics; (ii) support of policies to restrict unhealthy food, beverage and alcohol sponsorship of both elite and children's sports; (iii) who they thought should be responsible for implementing such policies; and (iv) their support for a funding system that allowed these companies to continue to give money to sport as long as they were not allowed to promote their brand at individual sports clubs. Parents who indicated they would be supportive of policies to limit unhealthy food and beverage and/or alcohol sponsorship of children's sport were provided with the statement 'Restricting unhealthy food and drink sponsorship might mean less funding for sport', and asked if they would still support these restrictions if it meant that fees for children's sport increased. Examples of elite sporting teams were provided to assist parents in answering questions. The child questionnaire addressed: (i) demographic characteristics, including interest in sport as a participant and/or spectator; (ii) perceptions of sponsorship, including recall of elite sport (favourite sporting team/person) and sporting event sponsors (attended or watched in the past year); and (iii) perceived sponsor-brand image, using 5-point semantic differential scales of cool-uncool, exciting-unexciting and fun-boring, with lower scores representing more positive ratings ('very cool/exciting/ fun'). Children were prompted to consider companies that had their logos on players' uniforms when recalling sport sponsors.

Parents' residential postcode was used to determine socioeconomic status, according to the Socio-Economic Indexes for Areas (SEIFA) Index of Advantage/Disadvantage ${ }^{(19)}$. SEIFA scores were stratified as high $(>1100)$, medium $(1000-1100)$ and low $(<1000)$ socio-economic areas.

\section{Procedures}

Surveys were conducted between February and May 2011. Only households with a child/children aged 5-16 years were included in the study. This was established during the introductory survey script. The interview was terminated and the household deemed ineligible if this criterion was not met. One parent/guardian from each household was asked to participate in the telephone survey (mean length $=14 \mathrm{~min}$ ). In households where an eligible child was resident, parents were asked if their child would participate in an online survey. Where more than one eligible child was present, the child with the most recent birthday was selected. Upon consent, a family email address was obtained and a link sent for the child to complete an online survey (mean length $=12 \mathrm{~min}$ ). Participating children were offered two movie vouchers. Recalled sponsors were cross-checked against sports teams/athletes/events websites. Questionnaires were piloted among parents ( $n$ 25) and children ( $n$ 8).

\section{Analyses}

Data were entered into the SPSS for Windows statistical software package version $17 \cdot 0$. Between-group comparisons were made according to demographic characteristics and children's interest in sport, using Pearson's $\chi^{2}$ tests. ANOVA with Scheffé post hoc testing was used to determine differences in children's recall of sponsors by interest in sport and frequency of watching teams/athletes compete, and to compare responses to semantic differential scales based on age, sex and sponsor type. $P$ values $<0.05$ were considered significant. 


\section{Results}

\section{Sample characteristics}

Parental response rate was 36\% ( $n$ 825). The greater proportion of parents was female $(68 \%)$ and in their $40 \mathrm{~s}$ (55\%). The majority of the sample was tertiary educated, having completed technical and further education/college (26\%) or university (43\%). However, $48 \%$ of parents lived in areas of the greatest social disadvantage. The completion rate for the child survey was 53\% ( $n$ 243). The sample comprised equal numbers of boys and girls, with a mean age of 13 (SD 1.8) years. Most children were either 'very interested' ( $55 \%$ ) or 'interested' ( $42 \%$ ) in sport.

\section{Parent survey}

Most parents were supportive of policies to restrict unhealthy food and beverage sponsorship of elite (71\%) and children's sport (76\%). Support for policies to restrict alcohol companies from sponsoring sport was higher ( $76 \%$ for elite and $86 \%$ for children's sport). Of parents who supported policies to restrict unhealthy food and beverage ( $n$ 624) and/or alcohol sponsorship of children's sport ( $n$ 669), the majority would continue to support these restrictions if it resulted in increased sport fees ( $87 \%$ and $91 \%$, respectively). There was no difference by parents' socio-economic status.

Most parents were 'likely' (39\%) or 'very likely' (42\%) to support an alternative funding model for children's sport, to allow unhealthy food, beverage and alcohol companies to sponsor sport if there was no visible branding at sports clubs. Of parents who did not support policies to limit unhealthy food and beverage sponsorship ( $n$ 195) or alcohol sponsorship ( $n$ 156) for children's sport, most supported this alternative funding model ( $71 \%$ and $72 \%$, respectively).

\section{Child survey}

\section{Awareness of sponsors}

Overall, $95 \%$ of children had a favourite elite sports team/ athlete and $65 \%$ of children could correctly recall at least one sponsor of this team/athlete. Of correctly recalled sponsors ( $n$ 428), $86 \%$ were non-food companies, $11 \%$ were food/beverage companies and 3\% were alcohol manufacturers/alcohol-related businesses. Children who watched this team/athlete compete in 'all' games during a season recalled more sponsors than those watching 'some' or 'none' of these games (mean $=2.5 v .1 .3$ and $0 \cdot 1 ; F(3,239)=7 \cdot 37, P<0 \cdot 001)$. Children who were 'very interested' in sport recalled more sponsors than those that were 'interested' or 'uninterested' (mean $=2 \cdot 1 v .1 \cdot 3$ and $0 \cdot 1 ; F(2,240)=5 \cdot 61, P<0 \cdot 01)$.

More than half of children (53\%) could recall at least one sporting event from the past year that had a food/ beverage sponsor. For the 227 named events, $201 \mathrm{food} /$ beverage sponsors were correctly recalled. The greatest

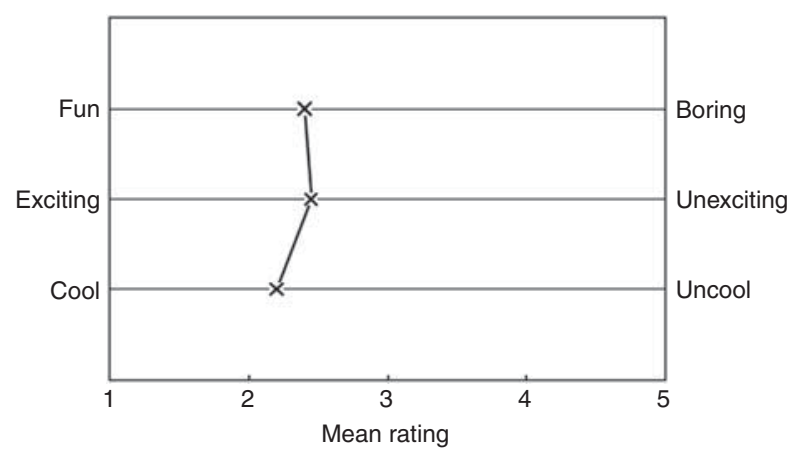

Fig. 1 Mean ratings on semantic differential scales (fun-boring, exciting-unexciting and cool-uncool) for recalled sponsors ( $n$ 494) of elite sports teams/athletes by children aged 10-16 years ( $n$ 243) from randomly sampled households in New South Wales, Australia, February-May 2011

proportion was companies that made sports drinks and soft drinks (49\%), fast-food restaurants (23\%) and alcohol manufacturers (10\%).

\section{Perceptions of sponsors}

Questions on perceptions of sponsors were asked for up to the first six sponsors recalled ( $n$ 494). For sponsors of elite sports teams/athletes, the mean rating on the semantic differential scales of cool-uncool, exciting-unexciting and fun-boring was 2, indicating that children rated these sponsors positively in regard to each attribute (Fig. 1), with no differences by age, sex or sponsor type.

For 39\% of recalled sponsors, children reported 'feeling better' about this company after it had sponsored this team/athlete. For companies from which children had previously purchased products ( $n$ 282), this sponsorship encouraged them to buy the product more in $41 \%$ of cases. Boys were more likely to report buying companies' products more following this sponsorship than girls ( $48 \%$ v. 33\%; $\left.\chi_{2}^{2}=8 \cdot 06, P=0 \cdot 02\right)$. There was no difference in reported purchases by age. For sporting events sponsors, children felt better about $26 \%$ of companies after this sponsorship, and were encouraged to buy sponsors' products more in $27 \%$ of cases.

While most children thought food and beverage companies only sponsored sport as a way of advertising, they also believed that sponsors wanted to help out sports clubs (Table 1). A minority of children considered the companies that sponsored their favourite sport when purchasing or consuming food, while more than half perceived that other children thought about sport sponsors when purchasing food.

\section{Discussion}

Parents indicated strong support for policies to restrict unhealthy food, beverage and alcohol companies from sponsoring both elite sporting teams/athletes and children's 
Table 1 Perceptions of sponsors and purchase and consumption behaviours as a result of sponsorship by children aged 10-16 years $(n$ 243) from randomly sampled households in New South Wales, Australia, February-May 2011

\begin{tabular}{lcccc}
\hline & \multicolumn{2}{c}{ Agree } & & Disagree \\
\cline { 3 - 5 } & $n$ & $\%$ & & \\
\hline Motivations of sponsors & & & & \\
$\quad$ To help out sports clubs & 153 & 63 & 90 & 37 \\
$\quad$ To advertise their products & 193 & 79 & 50 & 21 \\
Purchase intentions resulting from sponsorship & 137 & 56 & 106 & 44 \\
$\quad$ Think other children buy sponsors' products & 36 & 15 & 207 & 85 \\
$\quad$ Would always buy sponsors' products over another & 36 & 15 & 207 & 85 \\
$\quad$ Think about sponsors when l'm buying food or drink & & & 193 & 79 \\
$\quad$ Consumption behaviours resulting from sponsorship & 50 & 21 & & \\
$\quad$ Prefer to eat sponsors' products & & & & \\
\hline
\end{tabular}

own sports. There was particularly high support for restricting sponsorship of children's sport as well as alcohol sponsorship across all sporting levels. Currently in Australia, industry self-regulations on unhealthy food, beverage and alcohol sponsorship of children's sport are limited, while government regulations are non-existent. While industry regulations limit alcohol promotion at children's sporting events, this precludes businesses that sell alcohol, such as bars and hotels ${ }^{(20)}$. The two main industry codes for food marketing to children do not include sponsorship in their definition of $\operatorname{media}^{(21,22)}$

Parental support for restricting unhealthy sponsors of children's sport was further demonstrated by their willingness to bear the cost for such a policy to be introduced through increased sports fees. Parents' judgements about the relative benefits of sponsorship restrictions for children's sport, given the potential cost increase, are important considering that cost is a barrier to sports participation ${ }^{(23)}$.

The suggestion of an alternative funding model for children's sport, which could separate sponsors and sports clubs and potentially reduce the effect of this marketing on children, was also supported by parents. This could be established through the introduction of a brokerage system, or sport sponsorship fund, to manage the collection and distribution of corporate funding for sports clubs. While the fund model does not allow companies to derive direct public relations benefits by being associated with specific sports, it can provide potentially larger public relations reach through being associated with the fund itself. This model was particularly attractive to parents who did not support sponsorship policy interventions, and thus provides a compromise solution between community, sport, industry and health groups. Other examples of industry and community partnerships exist, such as the Stephanie Alexander Kitchen Garden Foundation ${ }^{(24)}$. This not-for-profit organisation is jointly funded by government and corporate contributions and supports primary schools in Australia to establish and maintain kitchen gardens, with links to the school curriculum, allowing students to grow, prepare and eat fresh fruit and vegetables.

Children had a high level of recall of sponsors of their favourite elite sporting teams or athletes in general, and about one-fifth were able to name a food or beverage sponsor. Recall of these elite sport sponsors was associated with children's interest in sport and frequency of watching the team/athlete compete. Similarly, surveys on children's awareness of tobacco brands and sponsorship have found an association between interest in sports and recall of sponsors ${ }^{(25)}$. Potentially, emotional involvement with an event may act as a modifying variable, impacting on brand recall ${ }^{(26)}$.

Children mainly regarded elite sport sponsors as being 'cool', 'fun' and 'exciting'. These positive brand-image associations influence brand preferences and usage, helping to form stronger emotional ties and trust of a brand $^{(27)}$. Indeed, children reported feeling better about many companies after they had sponsored their favourite elite sports team/athlete and were encouraged to buy the sponsor's product. This influence of sponsorship on brand perceptions and purchase intentions did not differ by age group, suggesting that both children and adolescents are influenced by this marketing. Half of children could also recall a food or beverage sponsor of a sporting event that they had seen or attended in the past year, and these were primarily manufacturers of sports drinks, soft drinks, fast food and alcohol. Similarly, children reported feeling better about these companies and were encouraged to buy sponsors' products following this event sponsorship.

The sampling and survey methods used were strengths of the present study. The large sample size and random sampling of participants extend earlier surveys on attitudes and awareness of sponsorship ${ }^{(14,16)}$. Use of the Electronic White Pages has been found to produce very similar demographic profiles to random digit dialling methods, with fewer calls required to achieve the sample size ${ }^{(28)}$. Limitations of this method include the exclusion of silent/ unlisted numbers and the restriction to households without landlines. However, approximately $90 \%$ of Australian residential dwellings have a landline telephone ${ }^{(29)}$. Therefore, this sampling method is a cost-effective and valid sampling method for telephone surveys. The use of an online survey was effective in reaching children as $79 \%$ of Australian children use the Internet, it is mostly accessed at home and 
its use increases to $96 \%$ for $12-14$-year-old children ${ }^{(17)}$. However, there may be some implications of using an online survey on the recruitment of children from more socially disadvantaged households, as Internet usage is lower among children with unemployed parents ${ }^{(17)}$.

It is possible that response rates may have introduced some selection bias and affected the internal validity of the research findings, as there could be a bias towards those most interested in the survey topic. In particular, $69 \%$ of parents were tertiary educated. However, $54 \%$ of 15-64-year-olds hold a bachelor degree or diploma in $\mathrm{NSW}^{(30)}$. As well, the response rate was similar to or higher than in other telephone surveys ${ }^{(31)}$. The use of the SEIFA Index of Advantage/Disadvantage to classify households and individuals according to socio-economic status should be interpreted with caution due to the heterogeneity of households within $\operatorname{areas}^{(32)}$. In fact, while one-third of parents with a university degree lived in high socio-economic areas compared with only $11 \%$ of those who did not complete high school, two-thirds of university educated parents also lived in low and medium socio-economic areas.

Further research is needed to quantify how much parents are willing to pay to restrict unhealthy sponsorship and if this would offset predicted sponsorship revenue losses. Further examination of children's perceived sponsor-brand attributes is also required. To this end, there are available measures, such as the Aaker scale, comprising forty-two brand-related traits ${ }^{(33)}$, or modified versions of this scale ${ }^{(34)}$. Finally, research should compare children's brand perceptions of sponsors and non-sponsors to better attribute brand image to sponsorship.

\section{Conclusions}

Australian parents support the restriction of unhealthy food, beverage and alcohol sponsorship of elite and children's sports. Restrictions could be arranged as either policies to guide appropriate sponsorship or alternative funding models to reduce promotions at sports clubs. Children's recall and positive associations of sponsors are important as these are linked to brand preferences and usage. This is concerning as the most frequently recalled food and beverage sponsors were manufacturers of sports drinks, soft drinks, fast food and alcohol.

\section{Acknowledgements}

This work was supported by Cancer Council NSW and the Australian Research Council (ARC Linkage Project: LP0989387). The authors declare no conflicts of interest. B.K. managed the data collection and analysis and drafted the manuscript. L.A.B., A.E.B., L.K., K.C. and B.J.S. provided strategic guidance for the study and the acquisition of funding. All authors were involved in the conception of the study, development of the surveys, and read and approved the final manuscript. The authors wish to thank participating parents and children for their contribution to this research. They also thank McNair Ingenuity Research, particularly Brianna Wallace and Matt Balogh for their diligent work in data collection.

\section{References}

1. Cairns G, Angus K \& Hastings G (2009) The Extent, Nature and Effects of Food Promotion to Children: A Review of the Evidence to December 2008. Prepared for the World Health Organization. Stirling: Institute for Social Marketing, University of Stirling.

2. World Health Organization (2010) Set of Recommendations on the Marketing of Foods and Non-Alcoholic Beverages to Children. Geneva: WHO.

3. Meenaghan J (1983) Commercial sponsorship. Eur J Mark 17, 5-71.

4. Gardner MP \& Shuman P (1988) Sponsorships and small business. J Small Bus Manage 26, 44-52.

5. Rowley J \& Williams C (2008) The impact of brand sponsorship of music festivals. Mark Intell Plann 26, 781-792.

6. Kelly B, Baur LA, Bauman AE et al. (2011) Tobacco and alcohol sponsorship of sporting events provide insights about how food and beverage sponsorship may affect children's health. Health Promot J Aust 22, 91-96.

7. Charlton A, While D \& Kelly S (1997) Boys' smoking and cigarette-brand-sponsored motor racing. Lancet 350, 1474.

8. Chebat J-C \& Daoud F (2003) Effects of F1 Grand Prix sponsorship by cigarette brands on adolescents' cognitive and behavioural responses. Int J Sports Mark Sponsorship $\mathbf{5}$, 93-104.

9. Vaidya SG, Naik UD \& Vaidya JS (1996) Effect of sports sponsorship by tobacco companies on children's experimentation with tobacco. BMJ 313, 400.

10. Shannon JR \& Turley LW (1997) The influence of in-arena promotions on purchase behavior and purchase intentions. Sport Mark Q 6, 53-59.

11. National Preventative Health Taskforce (2009) Preventing Alcobol-Related Harm in Australia: A Window of Opportunity. Canberra: Commonwealth Government of Australia; available at http://www.preventativehealth.org.au/internet/ preventativehealth/publishing.nsf/Content/tech-alcohol

12. O'Brien KS \& Kypri K (2008) Alcohol industry sponsorship and hazardous drinking among sportspeople. Addiction 103, 1961-1966.

13. Rehm J \& Kanteres F (2008) Alcohol and sponsorship in sport: some much-needed evidence in an ideological discussion. Addiction 103, 1967-1968.

14. Kelly B, Baur LA, Bauman AE et al. (2011) "Food company sponsors are kind, generous and cool": (mis)conceptions of junior sports players. Int J Behav Nutr Phys Act $\mathbf{8}, 95$.

15. Aitken PP, Leathar DS \& O'Hagan FJ (1985) Children's perceptions of advertisements for cigarettes. Soc Sci Med 21, 785-797.

16. Kelly B, Baur LA, Bauman AE et al. (2012) Restricting unhealthy food sponsorship: attitudes of the sporting community. Health Policy 104, 288-295.

17. Australian Bureau of Statistics (2009) 4901.0 - Children's Participation in Cultural and Leisure Activities, Australia. Canberra: ABS; available at http://www.abs.gov.au/ausstats/ abs@.nsf/Latestproducts/4901.0Main\%20Features4Apr\%202009? pendocument\&tabname $=$ Summary \&prodno $=4901.0 \&$ issue $=$ Apr $\% 202009 \&$ num $=\&$ view $=$

18. VicHealth (2010) Community attitudes survey: healthy community sporting environments. http://www.vichealth.vic. 
gov.au/ /media/About\%20Us/Attachments/HSE/Healthy SportingEnvironments_AttitudesSurvey_K-006-KN_FINAL.ashx (accessed September 2010).

19. Australian Bureau of Statistics (2006) Socioeconomic Indexes for Areas (SEIFA), Data Cube Only. Canberra: ABS.

20. Minister for Health Victoria, National Committee for the Review of Alcohol Advertising (2003) Review of the SelfRegulatory System for Alcohol Advertising. Report to the Ministerial Council of Drug Strategy. http://docs.health.vic.gov. au/docs/doc/2E4E141E5A719092CA2578A1000A1CB0/\$FILE/ ncraareport.pdf (accessed October 2011).

21. Australian Food and Grocery Council (2009) The Responsible Children's Marketing Initiative. http://www.afgc.org.au/ industry-codes/advertising-kids.html (accessed August 2010).

22. Australian Association of National Advertisers (2006) Food and Beverages Advertising and Marketing Communications Code. Canberra: Australian Association of National Advertisers; available at http://www.aana.com.au/pdfs/ FoodCode_Launch\%20Version.pdf

23. Hardy LL, Kelly B, Chapman K et al. (2010) Parental perceptions of barriers to children's participation in organised sport in Australia. J Paediatr Child Health 46, 197-203.

24. Stephanie Alexander Kitchen Garden Foundation (not dated) Partners. http://www.kitchengardenfoundation.org.au/about/ partners (accessed February 2012).

25. Sparks R (1999) Youth awareness of tobacco sponsorship as a dimension of brand equity. Int J Advert Mark Child $\mathbf{1}$, 193-218.

26. Turner K (2007) Alcohol and Sport Sponsorship: The Effect of Involvement and Congruence on Attitudes. Adelaide: The University of Adelaide.
27. Pecheux C \& Derbaix C (1999) Children and attitude toward the brand: a new measurement scale. J Advert Res 39, 19-27.

28. Wilson D, Starr G, Taylor A et al. (1999) Random digit dialling and Electronic White Pages samples compared: demographic profiles and health estimates. Aust $N Z J$ Public Health 23, 627-633.

29. Australian Communications and Media Authority (2009) Convergence and Communications. Report 1: Australian Housebold Consumers' Take-up and Use of Voice Communications Services. Canberra: Commonwealth of Australia; available at http://www.acma.gov.au/webwr/_assets/main/lib100068/ convergence_comms_rep-1_household_consumers.pdf

30. Australian Bureau of Statistics (2010) 6227.0 - Education and Work, Australia, May 2010. Canberra: ABS; available at http://www.abs.gov.au/AUSSTATS/abs@.nsf/DetailsPage/ 6227.0May\%202010?OpenDocument

31. O'Toole J, Sinclair M \& Leder K (2008) Maximising response rates in household telephone surveys. BMC Med Res Methodol 8, 71.

32. Australian Bureau of Statistics Methodology Advisory Committee (2007) Socio-economic indexes for individuals and families. http://www.abs.gov.au/AUSSTATS/abs@.nsf/Details Page/1352.0.55.086Jun\%202007?OpenDocument (accessed January 2012).

33. Azoulay A \& Kapferer JN (2003) Do brand personality scales really measure brand personality? J Brand Manage 11, 143-155.

34. Musante M, Milne GR \& McDonald MA (1999) Sport sponsorship: evaluating the sport and brand image match. Int J Sports Mark Sponsorship 1, 32-48. 